\title{
Autophagy gene fingerprint in human ischemia and reperfusion
}

\author{
Krishna K. Singh, PhD, ${ }^{\text {a }}$ Bobby Yanagawa, MD, PhD, ${ }^{\mathrm{d}}$ Adrian Quan, MPhil, ${ }^{\mathrm{a}}$ Rixin Wang, ${ }^{\mathrm{a}}$ Ankit Garg, ${ }^{\mathrm{a}}$ \\ Rishad Khan, ${ }^{\mathrm{a}}$ Yi Pan, MD, ${ }^{\mathrm{a}}$ Mark D. Wheatcroft, BSc, MBChB, MD, ${ }^{\text {bd }}$ Fina Lovren, PhD, ${ }^{\mathrm{a}}$ \\ Hwee Teoh, PhD, ${ }^{\mathrm{a}, \mathrm{c}}$ and Subodh Verma, MD, PhD, FRCSC, FAHA ${ }^{\mathrm{a}, \mathrm{d}}$
}

Objective: Autophagy is an evolutionary conserved adaptive response that is believed to promote cell survival in response to stressful stimuli via recycling of precursors derived from the degradation of endogenous cellular components. The autophagic molecular machinery is controlled by a large family of autophagy-related genes (ATGs) and downstream regulators. We sought to define the autophagy gene fingerprint associated with human ischemia and reperfusion (IR) injury using an intraoperative model developed by Sellke and colleagues.

Methods: Right atrial appendages, collected from human hearts before and after cardioplegic arrest and after reperfusion, were submitted for polymerase chain reaction (PCR) array, quantitative real-time PCR, and immunoblot analysis for autophagy proteins and their associated upstream regulators.

Results: Perioperative IR significantly upregulated 11 (13.1\%) and downregulated 3 (3.6\%) of 84 ATGs. Specifically, there were increases in the autophagy machinery components ATG4A, ATG4C, and ATG4D; tumor necrosis factor-related apoptosis-inducing ligand, MAPK8 and BCL2L1; and chaperone-mediated autophagy activity with increased heat shock protein (HSP) A8, HSP90AA1, and a-synuclein. Autophagy activity was confirmed through observations of higher LC3-I levels and an increase in the LC3-II/LC3-I ratio. Autophagy activation coincided with increased AMPK activation and decreased protein levels of the mammalian target of rapamycin, the latter a key negative regulator of autophagy.

Conclusions: We provide the first human cardiac fingerprint of autophagy gene expression in response to IR. These findings may inform on appropriate cell- and gene-based therapeutic approaches to limit aberrant cardiac injury. (J Thorac Cardiovasc Surg 2014;147:1065-72)

\section{Supplemental material is available online.}

Autophagy refers to a highly conserved cellular process for the turnover of organelles and proteins that occurs in all eukaryotic cells. It is generally activated as an adaptive response to stressful conditions (nutrient deprivation, hypoxia, and oxidative/genotoxic stress). Autophagy promotes cell survival through the recycling of precursors

\footnotetext{
From the Division of Cardiac Surgery, ${ }^{\mathrm{a}}$ Vascular \& Endovascular Surgery, ${ }^{\mathrm{b}}$ and Endocrinology \& Metabolism, ${ }^{\mathrm{c}}$ Keenan Research Centre in the Li Ka Shing Knowledge Institute at St Michael's Hospital, Toronto; and Department of Surgery, ${ }^{\mathrm{d}}$ University of Toronto, Toronto, Ontario, Canada.

This work was supported by grants from the Heart and Stroke Foundation of Canada and the Canadian Institutes of Health Research (to S.V.). B.Y. was the recipient of a Resident Research Grant from the Physicians' Services Incorporated Foundation. A.G. was a member of the Keenan Research Summer Student Program. S.V. is the Canada Research Chair in Atherosclerosis at the University of Toronto.

Disclosures: Authors have nothing to disclose with regard to commercial support.

K.K.S. and B.Y. share the position of first author.

Received for publication Jan 10, 2013; revisions received April 11, 2013; accepted for publication April 25, 2013; available ahead of print June 17, 2013.

Address for reprints: Subodh Verma, MD, PhD, FRCSC, FAHA, Attending Cardiac Surgeon, Associate Professor and Canada Research Chair in Atherosclerosis, Division of Cardiac Surgery, St Michael's Hospital, Suite 8-003, Bond Wing, 30 Bond St, Toronto, Ontario M5B 1W8, Canada (E-mail: vermasu@smh.ca). 0022-5223/ $\$ 36.00$

Copyright (c) 2014 by The American Association for Thoracic Surgery http://dx.doi.org/10.1016/j.jtcvs.2013.04.042
}

derived from the degradation of endogenous cellular components. Although classically a mechanism of cell preservation, excessive and uncontrolled autophagy can promote cell death. ${ }^{1}$ To date, autophagy has been implicated in a number of fundamental biological processes, including aging, immunity, development, tumorigenesis, cell death, and differentiation. ${ }^{1-12}$ Loss of autophagy has been implicated in various chronic diseases in which it is believed to represent a compensatory mechanism to maintain homeostasis during the early stages of disease progression. ${ }^{1-12}$

In the heart, induction of autophagy is proposed to be protective by facilitating the removal of damaged proteins and organelles and the recycling of proteins, glycogen, and fatty acids, thus providing energy for myofibers during stress and/or energy deprivation. ${ }^{1}$ Inasmuch as damaged mitochondria and cytochrome $\mathrm{c}$ release are potent triggers of apoptosis, the autophagic removal process is a critical antiapoptotic mechanism. ${ }^{13}$ Indeed, Garcia and colleagues ${ }^{14}$ have recently reported impaired cardiac autophagy in patients with postoperative atrial fibrillation.

Autophagy begins with the de novo formation of a cupshaped isolation double membrane (also called a phagophore or preautophagosome) that engulfs a portion of cytoplasm. The isolation membrane encloses to form a mature vesicle (autophagosome) that subsequently fuses with a lysosome, leading to the degradation of intra-autophagosomal 


$\begin{array}{ll}\text { Abbreviations and Acronyms } \\ \text { AMP } & =\text { adenosine monophosphate } \\ \text { AMPK } & =\text { adenosine monophosphate-activated } \\ & \text { protein kinase } \\ \text { ATG } & =\text { autophagy-related gene } \\ \text { AVR } & =\text { aortic valve replacement } \\ \text { Bcl-2 } & =\text { B-cell lymphocyte } 2 \\ \text { CABG } & =\text { coronary artery bypass graft } \\ \text { CP } & =\text { cardioplegia } \\ \text { CPB } & =\text { cardiopulmonary bypass } \\ \text { EIF2AK3 } & =\text { eukaryotic initiation factor } 2 \text { A kinase } \\ \text { HSP } & =\text { heat shock protein } \\ \text { IR } & =\text { ischemia-reperfusion } \\ \text { LC3 } & =\text { light chain } 3 \\ \text { MAPK8 } & =\text { mitogen-activated protein kinase } 8 \\ \text { mTor } & =\text { mammalian target of rapamycin } \\ \text { PCR } & =\text { polymerase chain reaction } \\ \text { PE } & =\text { phosphatidylethanolamine } \\ \text { qPCR } & =\text { quantitative polymerase chain reaction } \\ \text { SNCA } & =a \text {-synuclein } \\ \text { TNFSF10/ } & =\text { tumor necrosis factor-related } \\ \text { TRAIL } & \text { apoptosis-inducing ligand }\end{array}$

components by lysosomal hydrolases. ${ }^{15}$ The autophagy machinery is mainly regulated by autophagy-related genes (ATGs) that have been evolutionarily conserved from yeast to mammals. ${ }^{16,17}$ More than 30 ATGs have been cloned $^{2,3,8,10,12}$ and each critically guides induction of the isolation membrane, engulfment of cytoplasm, formation of the autophagic vesicles, and fusion with lysosome..$^{2,8,10,12,15}$

In the heart, baseline cardiac-specific loss of autophagy results in a hypertrophic and dilated cardiomyopathy phenotype with poor response to pressure overload. ${ }^{18}$ During acute stress, autophagy is triggered in response to cardiac ischemia-reperfusion (IR) where it is generally considered to be cardioprotective. ${ }^{19-21}$ Matsui and associates ${ }^{21}$ reported, in cardiomyocytes during IR injury, expression of the active form of the microtubule-associated protein light chain 3 (LC3), an essential component for autophagosome formation and a widely established marker of autophagy. Adenosine monophosphate (AMP)-activated protein kinase (AMPK)-dependent autophagy activation is reportedly protective during ischemia, although beclin-1-dependent activation appears to be detrimental during reperfusion. Experimental coronary artery ligation rapidly upregulates LC3 whereas the presence of autophagy inhibitor bafilomycin A1 has been associated with an increased infarct size. Together, these observations suggest an overall protective role for autophagy. ${ }^{19}$ The presence of autophagic vacuoles, cell death, and apoptosis has been demonstrated in chronically ischemic human myocardium through ultrastructural work. ${ }^{22}$ Interestingly, whereas mild ischemic insults trigger autophagy, severe, protracted ischemia tips the signaling balance to apoptotic and necrotic cell death. ${ }^{20}$ Finally, the nutrient-sensing molecule mammalian target of rapamycin (mTor) is a critical regulator of autophagy in nutrient deficiency models and in ischemic injury. ${ }^{21,23}$

Despite the extensive interest in autophagy as a mediator of the cardiac stress response, the majority of these data are derived from in vitro cell culture preparations and animal models. To the best of our knowledge, the autophagic gene profile in human cardiac tissues that have been subjected to IR has not been reported. In this report, we provide for the first time the human autophagy gene fingerprint in response to cardiac IR using a widely established intraoperative model of atrial IR injury. ${ }^{24}$

\section{MATERIALS AND METHODS \\ Study Population and Data Collection}

The study protocol was reviewed and approved by the Research Ethics Board of St Michael's Hospital. Participation was voluntary and informed consent obtained for all the cases. The original study cohort consisted of 9 patients. Another 7 individuals were enrolled to allow for confirmatory analyses. We used the model of human intraoperative atrial IR before and after cardiopulmonary bypass (CPB) validated by Dr Frank Sellke. ${ }^{24}$ Atrial samples $(\sim 5 \mathrm{~mm})$ were obtained from patients undergoing cardiac surgery with crossclamp/cardioplegia (CP) and CPB for coronary artery bypass graft $(\mathrm{CABG})$ surgery. Pre-CP/CPB right atrial appendages were isolated using a double purse-string suture method during venous cannulation. Two separate superficial and deep purse-string sutures were placed at the right atrial appendage, approximately 5 -mm apart. The tip of the right atrial appendage was harvested immediately (pre-CP/CPB) and the superficial purse-string was used. The heart was arrested with an aortic root infusion of highpotassium $(27 \mathrm{mEq} / \mathrm{L})$ blood $\mathrm{CP}$ solution. Blood $\mathrm{CP}$ was maintained with a low potassium formulation at $4{ }^{\circ} \mathrm{C}$. After weaning from bypass and a brief period of reperfusion (5-15 minutes), the deep purse-string suture was tied and the tissue between the 2 purse-string sutures harvested (post-CP/ $\mathrm{CPB}$ ). Tissue samples were flash frozen immediately and stored at $-80^{\circ} \mathrm{C}$.

\section{Autophagy Polymerase Chain Reaction Array Analysis and Quantitative Real-Time Polymerase Chain Reaction}

Initial transcript analyses were performed using samples from the original cohort of 9 individuals. RNA was extracted with a monophasic solution of TRIzol (Invitrogen, Carlsbad, Calif) and the RT ${ }^{2}$ First Strand Kit used for cDNA synthesis (SA Biosciences, Hilden, Germany). Quantitative real-time PCR (qPCR) was performed with $\mathrm{RT}^{2}$ qPCR Master Mixes in a StepOne Plus Real-Time PCR System (Applied Biosystems, Foster City, Calif). Gene expression profiles were generated with 96-well arrays containing human ATGs (PAHS; 084, SA Biosciences) using the Human Autophagy $\mathrm{RT}^{2}$ Profiler PCR Array (SA Biosciences) containing 84 ATGs in accordance with the manufacturer's instructions. Threshold cycle data were analyzed with the $\mathrm{RT}^{2}$ Profiler software (version 3.4; SA Biosciences). The relative gene expression was normalized with multiple control genes and the fold change in gene expression within post-CP/CPB samples compared with those in the corresponding control pre-CPB samples. Genes that had undergone significant upregulation or downregulation were identified from this initial work; and their temporal expression was mapped via real-time PCR with samples from the original patient cohort $(\mathrm{N}=5-6)$ and confirmed in those from an additional 7 patients. 


\section{Western Blotting}

Total protein, extracted with ice-cold RIPA buffer (Sigma Chemical Co, St Louis, Mo) containing a protease inhibitor cocktail (Roche, Basel, Switzerland), was quantified with the Bio-Rad Protein Assay Reagent. Protein samples $(40 \mu \mathrm{g})$ were separated by sodium dodecylsulfate-polyacrylamide gel electrophoresis, transferred to nitrocellulose membranes, and probed with antibodies from Cell Signaling (p62, caspase-3, LC3, mTor, phospho-mTor, AMPK, and phosho-AMPK; all at a 1:1000 dilution) or Millipore (glyceraldehyde 3-phosphate dehydrogenase, 1:4000). After incubation with the appropriate horseradish peroxidase-associated secondary antibodies (Santa Cruz Biotechnology, Santa Cruz, Calif), signals were visualized with an enhanced chemiluminescence detection system (Amersham Bioscience, Piscataway, NJ) and quantified by densitometry.

\section{Statistical Analysis}

Unless otherwise stated, data are presented as means \pm standard deviation for number of samples. The Student $t$ test was applied for comparison of means of 2 groups.

\section{RESULTS \\ Baseline Patient Characteristics and Intraoperative Details}

Baseline characteristics of the original patient cohort are shown in Table 1. Information on the additional confirmatory patient cohort is provided in Table E1. All 9 of the original patients were men, of whom $44.4 \%$ had hypertension, $55.6 \%$ had dyslipidemia, and $11.1 \%$ had diabetes. Cardiac medications included angiotensin-converting enzyme inhibitors or angiotensin receptor blockers in $44.4 \%$ of subjects, statin(s) in $88.9 \%$, and $\beta$-blockers in $88.9 \%$ preoperatively. Five patients underwent CABG surgery, 1

TABLE 1. Baseline characteristics and intraoperative details

\begin{tabular}{lc}
\hline & $\mathbf{N}=\mathbf{9}$ \\
\hline Age (y) & $65.1 \pm 6.3$ \\
Male & $100(9)$ \\
Clinical history & \\
$\quad$ Hypertension & $44.4(4)$ \\
Dyslipidemia & $55.6(5)$ \\
Diabetes & $11.1(1)$ \\
Smoking history & $22.2(2)$ \\
Heart failure & $11.1(1)$ \\
Medications & \\
ACE inhibitor/ARB & $44.4(4)$ \\
Statin & $88.9(8)$ \\
Beta-blocker & $88.9(8)$ \\
Calcium channel blocker & $11.1(1)$ \\
Surgical procedure & \\
CABG & $55.6(5)$ \\
AVR & $11.1(1)$ \\
AVR and CABG & $33.3(3)$ \\
Degree of ischemia & \\
$\quad$ CPB (min) & $96.2 \pm 26.2$ \\
Crossclamp/CP (min) & $77.7 \pm 25.3$ \\
Reperfusion (min) & $16.5 \pm 7.4$ \\
\hline Data are presented as n $\%$ or mean \pm standard deviation. & $A C E$ inhibitor, \\
Angiotensin-converting enzyme inhibitor; $A R B$, angiotensin receptor blocker; $A V R$, \\
aortic valve replacement; $C A B G$, coronary artery bypass graft; $C P B$, cardiopulmo- \\
nary bypass; $C P$, cardioplegia. &
\end{tabular}

underwent aortic valve replacement (AVR), and 3 patients underwent combined CABG and AVR. Mean CPB, CP, and reperfusion times were $96.2 \pm 26.2,77.7 \pm 25.3$, and $16.5 \pm 7.4$ minutes, respectively, representing a mild and acute IR insult.

\section{IR Alters the Expression of ATGs in Human Atrial Tissue}

After IR, 30\% (25/84) of the ATGs examined with the Human Autophagy RT ${ }^{2}$ Profiler PCR Array demonstrated at least a 1.5 -fold change in expression. Real-time PCR analyses confirmed that among the 25 ATGs identified, 11 ( $13.1 \%$ of the 84 genes studied) were significantly upregulated and 3 (3.6\% of the set of 84 genes) markedly downregulated after IR (Table 2, Figures 1-4). Subsequent real-time PCR analysis using samples from the confirmatory cohort indicated that 8 of the 10 genes that were examined in both groups had post-IR expression patterns that mirrored those in the original cohort (Table E2).

\section{IR Induces Expression of Autophagy Machinery in Human Atrial Tissue}

Expression of the ATG4 cysteine proteases ATG4A, ATG4C, and ATG4D was significantly increased after IR by PCR array and real-time PCR (Table 2, Table E2, Figure $1, A, C$, and $D$ ). There was also enhanced expression of the ATG4 substrates, MAPLC3B (LC3B), $\gamma$-aminobutyric acid type A receptor-associated protein (GABARAP) 2 and GABARAP (Table 2; Table E2; Figure 1,E), the last of

TABLE 2. Select autophagy genes either upregulated or downregulated by $\geq 1$.5-fold after cardiopulmonary bypass/cardioplegia (CPB/CP) $(N=9)$

\begin{tabular}{|c|c|c|}
\hline Gene & Fold change & $P$ value (before vs after $\mathrm{CPB} / \mathrm{CP}$ ) \\
\hline Caspase-3 & 2.6 & .02 \\
\hline EIF2AK3 & 2.5 & .05 \\
\hline SNCA & 2.5 & .04 \\
\hline GABARAPL2 & 2.2 & .02 \\
\hline DRAM2 & 2.0 & .04 \\
\hline WIPI1 & 2.0 & .05 \\
\hline ATG4D & 2.0 & .05 \\
\hline MAPK8 & 2.0 & .05 \\
\hline HSP90AA1 & 1.9 & .03 \\
\hline BCL2L1 & 1.8 & .04 \\
\hline TNFSF10 & 1.7 & .02 \\
\hline GAA & -1.5 & .04 \\
\hline mTOR & -1.7 & .02 \\
\hline ATG4B & -1.8 & .01 \\
\hline \multicolumn{3}{|c|}{$\begin{array}{l}C P B \text {, Cardiopulmonary bypass; } C P \text {, cardioplegia; } E I F 2 A K 3 \text {, eukaryotic initiation factor } \\
2 \text { A kinase; SNCA, a-synuclein; MAPK8, mitogen-activated protein kinase } 8 \\
H S P 90 A A 1 \text {, heat shock protein } 90 \mathrm{kDa} \text { alpha (cytosolic), class A member } 1 ; B C L 2 L 1 \text {, } \\
\text { B-cell lymphocyte 2-like protein-1; TNFSF10, tumor necrosis factor; GAA, acid-alpha } \\
\text { glucosidase; } m T O R \text {, mammalian target of rapamycin; GABARAPL2, GABA(A) recep- } \\
\text { tor-associated protein-like } 2 ; D R A M 2 \text {, DNA-damage regulated autophagy modulator } \\
2 \text {; WIPII, WD repeat domain, phosphoinositide interacting } 1 ; A T G 4 D \text {, autophagy- } \\
\text { related 4D, cysteine peptidase; } A T G 4 B \text {, autophagy-related } 4 \mathrm{~B} \text {, cysteine peptidase. }\end{array}$} \\
\hline
\end{tabular}



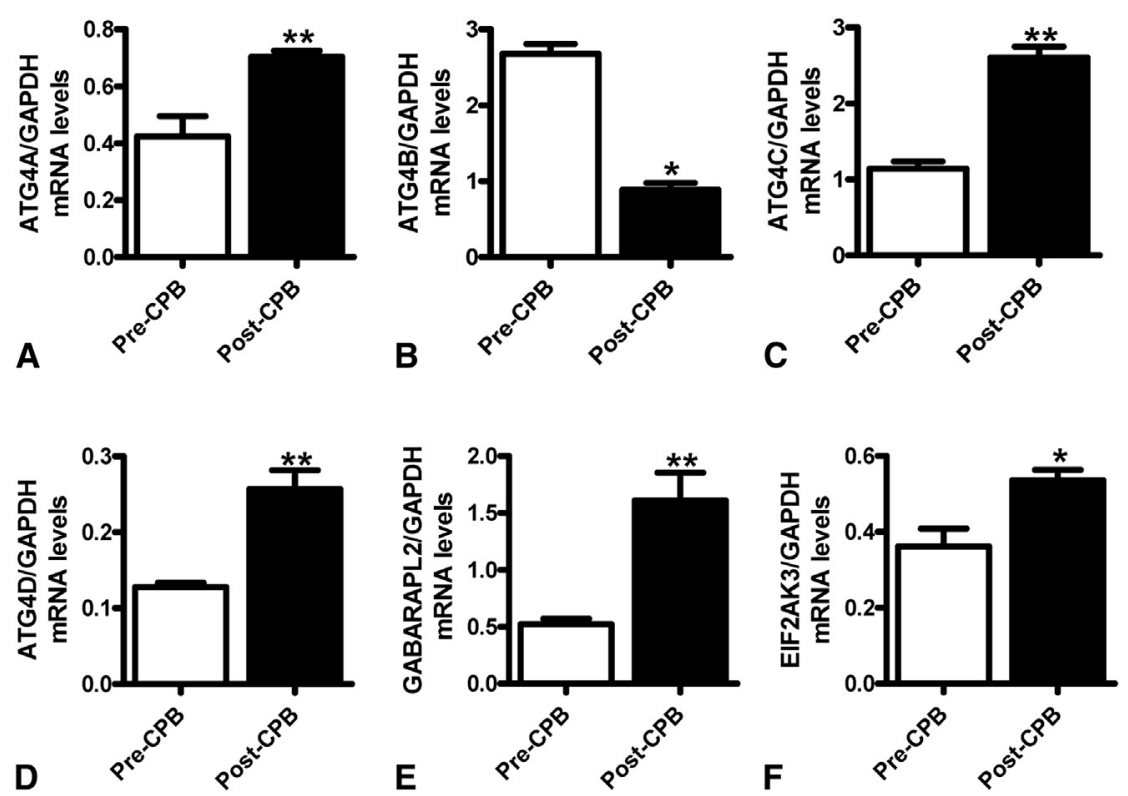

FIGURE 1. Ischemia-reperfusion alters the expression of autophagy machinery genes in the human myocardium. Histograms represent quantitative realtime polymerase chain reaction data for ATG4A (A), ATG4B (B), ATG4C (C), ATG4D (D), GABARAPL2 (E), and EIF2AK3 (F). GAPDH was the reference gene. $\mathrm{n}=6$ per group. ${ }^{*} P<.05$, $* * P<.01$ versus data from pre-cardiopulmonary bypass/cardioplegia samples. $G A P D H$, Glyceraldehyde 3-phosphate dehydrogenase; $C P B$, cardiopulmonary bypass; $A T G$, autophagy-related gene; $m R N A$, messenger RNA.

which undergoes conjugation with phosphatidylethanolamine (PE), a key step in autophagosome biogenesis. In contrast, ATG4B, responsible for ATG8 cleavage and ATG8-PE complex deconjugation and ATG8 membrane release, was downregulated (Table 2; Figure 1, B). Autophagy activation was associated with increased protein kinase R-like eukaryotic initiation factor 2 A kinase (EIF2AK3) expression indicating endoplasmic reticulum stress after IR injury (Table 2; Figure 1, F).

\section{IR Induces Expression of Autophagy and Apoptosis Markers}

We report antiapoptotic signaling with increased expression of tumor necrosis factor-related apoptosis-inducing ligand (TNFSF10/TRAIL), mitogen-activated protein kinase 8 (MAPK8), and B-cell lymphocyte 2 (Bcl-2)-like protein-1 (BCl2L1/Bcl-xL) (Table 2; Figure 2, $A$ and $B$ ), and decreased BAK1 expression (Figure 2,D). Transcript and protein levels of caspase-3 were increased (Table 2; Figure 2, E). Thus, autophagy-related antiapoptotic and proapoptotic genes are expressed concurrently.

\section{IR Induces Chaperone-Mediated Autophagy in Human Atrial Tissues}

Chaperone-mediated autophagic activity is the only type of autophagy capable of selective targeting of autophagy substrates. We observed increased expression of the molecular chaperones heat shock protein (HSP) A8 and HSP90AA1 after IR injury (Table 2; Figure 3, A).
Furthermore, $a$-synuclein (SNCA), which serves to integrate presynaptic signaling, membrane trafficking, and promote chaperone-mediated autophagic, was also upregulated after IR injury (Table 2; Figure 3, $B$ ).

\section{IR Induces AMPK-mTOR Axis in Human Atrial Tissue}

IR was associated with increases in AMPK activation (Figure 4, A) and suppressed transcript and protein levels of mTor, a potent inhibitor of autophagy (Table 2; Figure $4, B$ and $C$ ). There was a concomitant dramatic increase in LC3-I protein levels with significant elevations in LC3-II/LC3-I ratio, indicating autophagy activity (Figure 4, D). Glycogen degrading lysosomal hydrolase acid-alpha glucosidase (GAA) gene expression was decreased after IR (Figure 4,E). Western blot analysis revealed no significant change in p62 expression after IR injury (Figure 4, F).

\section{DISCUSSION}

This is the first report demonstrating the global pattern of autophagy gene activation in human myocardium after acute IR injury. The key findings are (1) increased ATG gene expression; (2) dramatically increased autophagic activity as evidenced by a shift in the LC3-II/LC3-I ratio; and (3) activation of known upstream AMPK signaling and associated loss of mTor inhibition, suggesting a regulatory mechanism. 

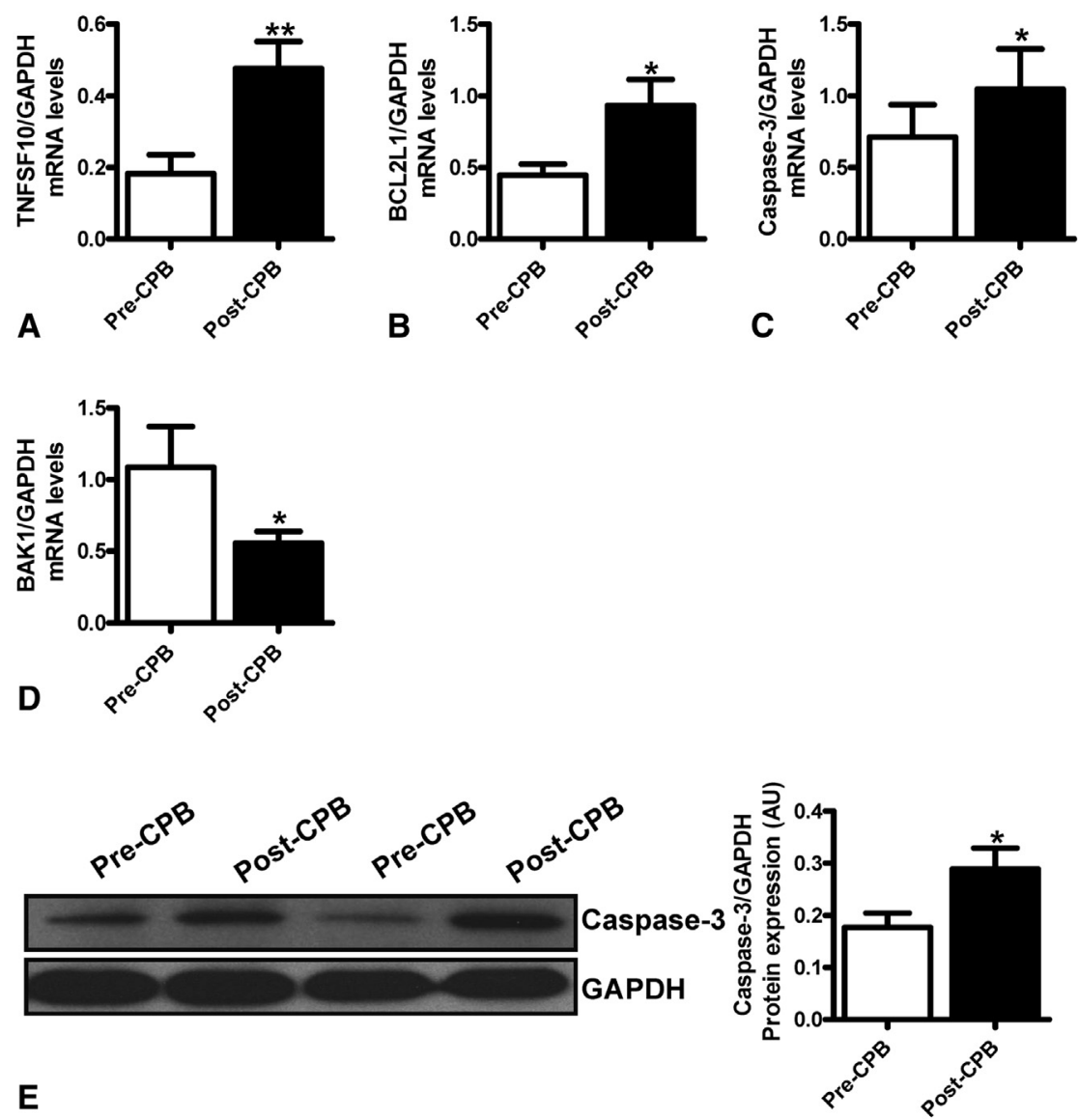

FIGURE 2. Ischemia-reperfusion alters the expression of coregulators of autophagy and apoptosis in the human myocardium. Histograms represent quantitative real-time polymerase chain reaction data for TNFSF10 (A), BCL2L1 (B), caspase-3 (C), and BAK (D). GAPDH acted as the reference gene. E, Western blot and semiquantitative analysis of caspase- 3 levels. GAPDH was the loading reference protein. $\mathrm{n}=6$ per group. $* P<.05$, $* * P<.01$ versus data from precardiopulmonary bypass/cardioplegia samples. $G A P D H$, Glyceraldehyde 3-phosphate dehydrogenase; $C P B$, cardiopulmonary bypass; $T N F S F$, tumor necrosis factor; $B C L 2 L 1$, B-cell lymphocyte 2-like protein-1; $B A K$, B-cell lymphocyte 2 homologous antagonist/killer; $m R N A$, messenger RNA; $A U$, arbitrary units.

We used a widely validated model of human atrial cardiac ischemia and reperfusion during CPB with CP arrest, followed by reperfusion. Given the variability in studies
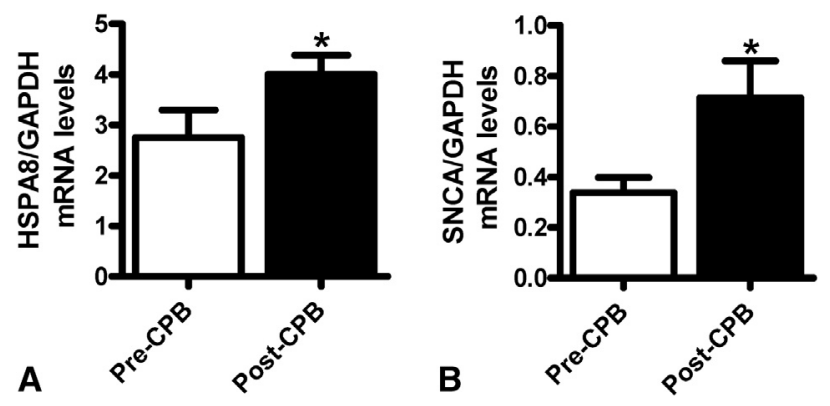

FIGURE 3. Ischemia-reperfusion induces chaperone-mediated autophagy in the human myocardium. Histograms represent quantitative real-time polymerase chain reaction data for HSPA8 (A) and SNCA (B). GAPDH was the reference gene. $\mathrm{n}=6$ per group. $* P<.05$ versus data from pre-cardiopulmonary bypass/cardioplegia samples. GAPDH, Glyceraldehyde 3-phosphate dehydrogenase; $C P B$, cardiopulmonary bypass; $S N C A$, $a$-synuclein; HSPA8, heat shock $70 \mathrm{kDa}$ protein $8 ; m R N A$, messenger RNA. of human genomics, the strength of this model is that each patient acted as his or her own control in determination of differential gene expression. The degree of injury has previously been shown to be sufficient to trigger cardiomyocyte injury and acute cardioprotective responses by our group and others. ${ }^{24,25}$

In this report, we demonstrate increased expression of several genes of the autophagy machinery. Using a PCR array system to study samples from 9 patients, we identified 25 ATGs that were either upregulated or downregulated at least 1.5 -fold after IR insult. Subsequent real-time PCR analysis in these samples and those from an additional 7 individuals confirmed that the expression of key ATGs is associated with IR injury. The central step in autophagosome formation is cleavage of ATG8 and conjugation to PE for autophagosome membrane extension, fusion, and the eventual enclosure of the membrane for vesicle formation. ${ }^{26}$ The ATG4 homologs, which were upregulated after IR injury, are necessary for ATG8 cleavage, protein targeting to membranes/vacuoles, protein transport, and for protease 


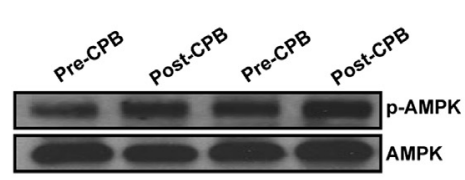

A

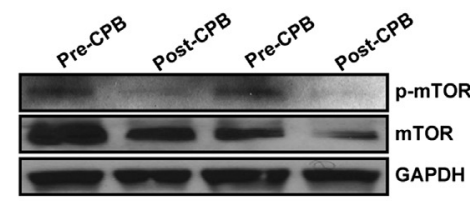

C

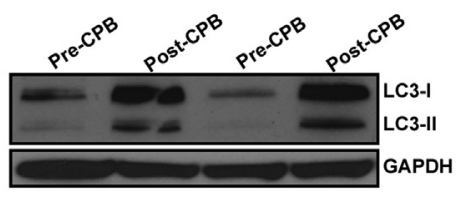

D

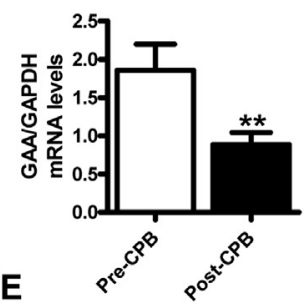

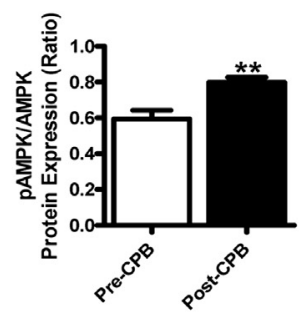
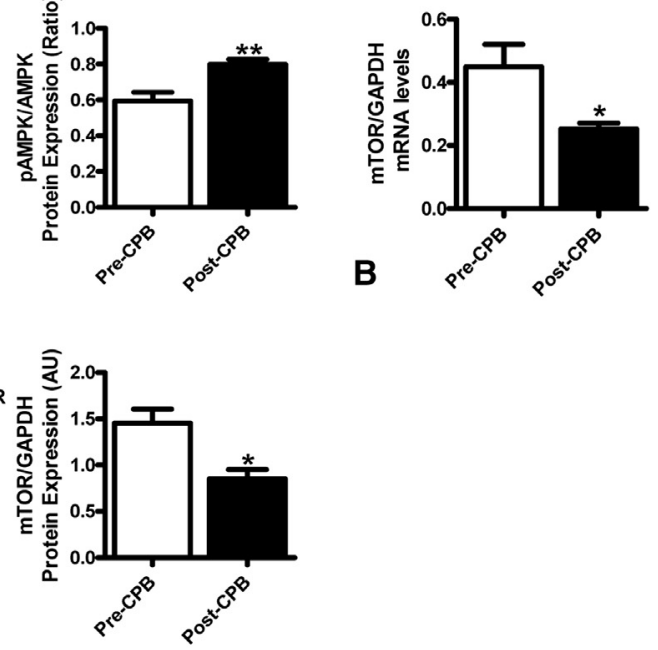
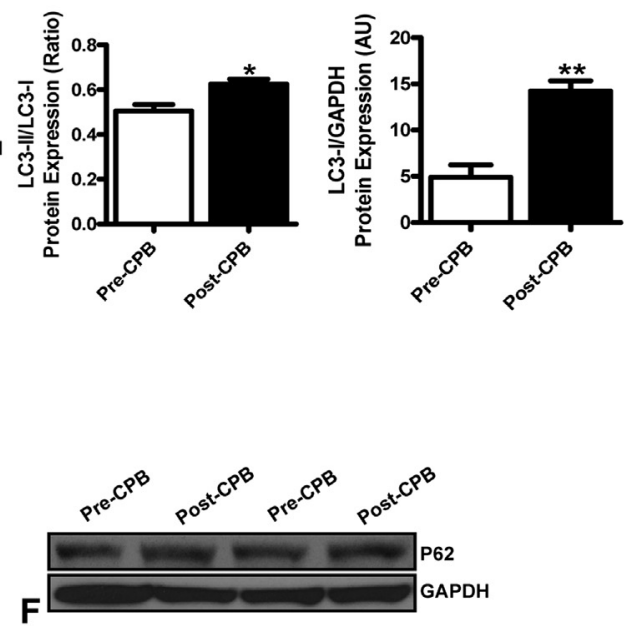

FIGURE 4. Ischemia-reperfusion is associated with AMPK-mediated reductions in mTor activation and increased autophagy in the human myocardium. Atrial samples were submitted for either Western blot analysis or qPCR. Representative immunoblots and semiquantitative results are shown for AMPK/pAMPK (A), mTOR (C), LC3 (D), and p62 (F). qPCR results are shown for mTOR (B) and GAA (E). GAPDH was the reference gene/protein. $\mathrm{n}=5$ per group. $* P<.05$, $* * P<.01$ versus data from pre-cardiopulmonary bypass/cardioplegia samples. GAPDH, Glyceraldehyde 3-phosphate dehydrogenase; $C P B$, cardiopulmonary bypass; $A M P K$, adenosine monophosphate-activated protein kinase; mTOR, mammalian target of rapamycin; $p-m T O R$, phospho-mammalian target of rapamycin; $L C$, light chain; $p$ - $A M P K$, phosphorylated adenosine monophosphate-activated protein kinase; $A U$, arbitrary units.

activity. ${ }^{27}$ GABARAP is an ATG8-related protein involved in LC3-II generation. ${ }^{28}$ The endoplasmic reticulum membrane-associated protein, EIF2AK3, is activated by misfolded proteins, a signal of endoplasmic reticulum stress, which then acts as a strong inducer of autophagy. ${ }^{29} \mathrm{We}$ also observed the higher expression of SNCA demonstrating activation of the chaperone-mediated autophagic pathway, which selectively degrades cytosolic proteins containing a targeting motif recognized by a cytosolic chaperone complex.

Although the role of autophagy in promoting survival is widely established, there has been some debate as to whether autophagy may also contribute to cell death. We found significantly increased levels of MAPK8, TNFSF10, and antiapoptotic $\mathrm{BCl} 2 \mathrm{~L} 1$ as well as decreases in proapoptotic
BAK1 expression. It is known that TNFSF10/TRAIL induces cytoprotective MAPK8/JNK-dependent autophagy. ${ }^{30}$ Apoptosis activation has previously been demonstrated in this human IR model ${ }^{31}$ and, consistent with this, our data confirm increased caspase- 3 expression. Accordingly, we provide evidence of both proapoptotic and antiapoptotic signaling in acute human IR injury. Whether autophagy is protective or proapoptotic remains to be determined and may depend on the balance of contribution during ischemia versus reperfusion.

We found activation of the AMPK-mTor signaling axis, a critical regulator of the balance between survival and apoptotic signals, mitochondrial bioenergetics, autophagy, and inflammation. Consistent with our findings, previous studies have shown that ischemia activates the 
energy-sensing kinase AMPK, a negative regulator of mTOR, the latter being a potent inhibitor of autophagy. ${ }^{32}$ This was associated with a marked increase in the expression of LC3 and in the conversion of LC3-I to LC3-II, a key step in autophagosome formation. ${ }^{33}$ Western blot analysis revealed no significant changes in the protein levels of the autophagy flux marker p62, indicating that further studies focused on characterizing the autophagy pathway in human IR conditions is warranted.

\section{Translational Implications and Limitations}

Numerous randomized controlled trials in the oncology field have evaluated the safety and efficacy of inhibition or augmentation of autophagy. ${ }^{34}$ At the experimental level, relatively nonspecific manipulation of autophagy has been shown to alter infarct size in coronary ligation models, suggesting the possibility of targeted treatment for human IR injury. ${ }^{21}$ Activation of autophagy via pharmacologic means in a porcine coronary ligation model using the CPY450 inhibitor chloramphenicol succinate was associated with a 6-fold increase in LC3-II expression and 50\% reduction in infarct size. ${ }^{35}$ Furthermore, a porcine model of ischemic preconditioning was associated with augmented beclin-1 and LC3-II expression, further supporting the potential therapeutic benefit of autophagy. ${ }^{36}$ The present findings support the continued study of global autophagy activation to limit cardiac failure in response to IR. An alternative strategy may be to directly manipulate key autophagic machineryrelated molecules such as Foxo, ATG4A, ATG4C, and ATG4D or regulatory signaling pathways such as the AMPK-mTOR axis using cell or gene therapy.

The present study has some important limitations. The gene and protein expression studies provide only a snapshot of expression without information on the temporal expression pattern. Furthermore, we are unable to differentiate the individual contributions of ischemia and reperfusion to the overall autophagy expression profile. The relatively small sample size and clinical variability between and within the group may account for some of the inconsistency in the gene expression profile between the 2 patient cohorts. Indeed, additional work is needed to confirm our findings and to establish their respective pathophysiologic and functional significance.

\section{References}

1. Ravikumar B, Sarkar S, Davies JE, Futter M, Garcia-Arencibia M, GreenThompson ZW, et al. Regulation of mammalian autophagy in physiology and pathophysiology. Physiol Rev. 2010;90:1383-435.

2. Behrends C, Sowa ME, Gygi SP, Harper JW. Network organization of the human autophagy system. Nature. 2010;466:68-76.

3. Deretic V, Levine B. Autophagy, immunity, and microbial adaptations. Cell Host Microbe. 2009;5:527-49.

4. Hailey DW, Rambold AS, Satpute-Krishnan P, Mitra K, Sougrat R, Kim PK, et al. Mitochondria supply membranes for autophagosome biogenesis during starvation. Cell. 2010;141:656-67.

5. Kraft C, Peter M, Hofmann K. Selective autophagy: ubiquitin-mediated recognition and beyond. Nat Cell Biol. 2010;12:836-41.
6. Kroemer G, Marino G, Levine B. Autophagy and the integrated stress response. Mol Cell. 2010;40:280-93.

7. Levine B, Mizushima N, Virgin HW. Autophagy in immunity and inflammation. Nature. 2011;469:323-35.

8. Mizushima N, Levine B, Cuervo AM, Klionsky DJ. Autophagy fights disease through cellular self-digestion. Nature. 2008;451:1069-75.

9. Saitoh T, Akira S. Regulation of innate immune responses by autophagy-related proteins. J Cell Biol. 2010;189:925-35.

10. Virgin HW, Levine B. Autophagy genes in immunity. Nat Immunol. 2009;10: 461-70.

11. Yang Z, Klionsky DJ. Mammalian autophagy: core molecular machinery and signaling regulation. Curr Opin Cell Biol. 2010;22:124-31.

12. Levine B, Kroemer G. Autophagy in the pathogenesis of disease. Cell. 2008;132: 27-42.

13. Ravikumar B, Berger Z, Vacher C, O'Kane CJ, Rubinsztein DC. Rapamycin pre-treatment protects against apoptosis. Hum Molecular Genet. 2006;15 1209-16.

14. Garcia L, Verdejo HE, Kuzmicic J, Zalaquett R, Gonzalez S, Lavandero S, et al. Impaired cardiac autophagy in patients developing postoperative atrial fibrillation. J Thorac Cardiovasc Surg. 2012;143:451-9.

15. Periyasamy-Thandavan S, Jiang M, Schoenlein P, Dong Z. Autophagy: molecular machinery, regulation, and implications for renal pathophysiology. Am J Physiol Renal Physiol. 2009;297:F244-56.

16. Nakatogawa H, Suzuki K, Kamada Y, Ohsumi Y. Dynamics and diversity in autophagy mechanisms: lessons from yeast. Nat Rev Mol Cell Biol. 2009;10:458-67.

17. Xie Z, Klionsky DJ. Autophagosome formation: core machinery and adaptations. Nat Cell Biol. 2007;9:1102-9.

18. Nakai A, Yamaguchi O, Takeda T, Higuchi Y, Hikoso S, Taniike M, et al. The role of autophagy in cardiomyocytes in the basal state and in response to hemodynamic stress. Nat Med. 2007;13:619-24.

19. Kanamori H, Takemura G, Goto K, Maruyama R, Ono K, Nagao K, et al. Autophagy limits acute myocardial infarction induced by permanent coronary artery occlusion. Am J Physiol Heart Circ Physiol. 2011;300:H2261-71.

20. Loos B, Genade S, Ellis B, Lochner A, Engelbrecht AM. At the core of survival autophagy delays the onset of both apoptotic and necrotic cell death in a model of ischemic cell injury. Exp Cell Res. 2011;317:1437-53.

21. Matsui Y, Takagi H, Qu X, Abdellatif M, Sakoda H, Asano T, et al. Distinct roles of autophagy in the heart during ischemia and reperfusion: roles of AMPactivated protein kinase and Beclin 1 in mediating autophagy. Circ Res. 2007; 100:914-22.

22. Elsasser A, Vogt AM, Nef H, Kostin S, Mollmann H, Skwara W, et al. Human hibernating myocardium is jeopardized by apoptotic and autophagic cell death. $J$ Am Coll Cardiol. 2004;43:2191-9.

23. Zoncu R, Bar-Peled L, Efeyan A, Wang S, Sancak Y, Sabatini DM. mTORC1 senses lysosomal amino acids through an inside-out mechanism that requires the vacuolar H(+)-ATPase. Science. 2011;334:678-83.

24. Clements RT, Sodha NR, Feng J, Mieno S, Boodhwani M, Ramlawi B, et al Phosphorylation and translocation of heat shock protein 27 and alphaBcrystallin in human myocardium after cardioplegia and cardiopulmonary bypass. J Thorac Cardiovasc Surg. 2007;134:1461-70.

25. Shukla PC, Singh KK, Quan A, Al-Omran M, Teoh H, Lovren F, et al. BRCA1 is an essential regulator of heart function and survival following myocardial infarction. Nat Comm. 2011;2:593.

26. Satoo K, Noda NN, Kumeta H, Fujioka Y, Mizushima N, Ohsumi Y, et al. The structure of Atg4B-LC3 complex reveals the mechanism of LC3 processing and delipidation during autophagy. EMBO J. 2009;28:1341-50.

27. Li M, Hou Y, Wang J, Chen X, Shao ZM, Yin XM. Kinetics comparisons of mammalian Atg4 homologues indicate selective preferences toward diverse Atg8 substrates. J Biol Chem. 2011;286:7327-38

28. Kabeya Y, Mizushima N, Yamamoto A, Oshitani-Okamoto S, Ohsumi Y, Yoshimori T. LC3, GABARAP and GATE16 localize to autophagosomal membrane depending on form-II formation. J Cell Sci. 2004;117:2805-12.

29. Buchberger A, Bukau B, Sommer T. Protein quality control in the cytosol and the endoplasmic reticulum: brothers in arms. Mol Cell. 2010;40:238-52.

30. He W, Wang Q, Xu J, Xu X, Padilla MT, Ren G, et al. Attenuation of TNFSF10/ TRAIL-induced apoptosis by an autophagic survival pathway involving TRAF2 and RIPK1/RIP1-mediated MAPK8/JNK activation. Autophagy. 2012;8: 1811-21.

31. Ramlawi B, Feng J, Mieno S, Szabo C, Zsengeller Z, Clements R, et al. Indices of apoptosis activation after blood cardioplegia and cardiopulmonary bypass. Circulation. 2006;114:I257-63. 
32. Takagi H, Matsui Y, Hirotani S, Sakoda H, Asano T, Sadoshima J. AMPK mediates autophagy during myocardial ischemia in vivo. Autophagy. 2007;3:405-7.

33. Mizushima N, Yoshimori T, Levine B. Methods in mammalian autophagy research. Cell. 2010;140:313-26.

34. Levy JM, Thorburn A. Targeting autophagy during cancer therapy to improve clinical outcomes. Pharmacol Ther. 2011;131:130-41.
35. Sala-Mercado JA, Wider J, Undyala VV, Jahania S, Yoo W, Mentzer RM Jr, et al. Profound cardioprotection with chloramphenicol succinate in the swine model of myocardial ischemia-reperfusion injury. Circulation. 2010;122: S179-84.

36. Yan L, Sadoshima J, Vatner DE, Vatner SF. Autophagy in ischemic preconditioning and hibernating myocardium. Autophagy. 2009;5:709-12. 
TABLE E1. Baseline characteristics and intraoperative details of the confirmatory patient cohort

\begin{tabular}{lc}
\hline & $\mathbf{N}=\mathbf{7}$ \\
\hline Age (y) & $65.4 \pm 16.4$ \\
Male & $85.7(6)$ \\
Clinical history & \\
Hypertension & $85.7(6)$ \\
Dyslipidemia & $71.4(5)$ \\
Diabetes & $42.9(3)$ \\
Smoking history & $28.6(2)$ \\
Heart failure & $14.3(1)$ \\
Medications & \\
ACEi/ARB & $14.3(1)$ \\
Statin & $71.4(5)$ \\
Beta-blocker & $42.9(3)$ \\
Calcium channel blocker & $28.6(2)$ \\
Surgical procedure & \\
CABG & $71.4(5)$ \\
AVR & $14.3(1)$ \\
AVR and CABG & $14.3(1)$ \\
Degree of Ischemia & \\
CPB (min) & \\
Crossclamp/CP (min) & $96.0 \pm 33.3$ \\
Reperfusion (min) & $82.9 \pm 29.8$ \\
\hline Data are presented as n (\%) or mean \pm standard deviation. & $A C E$ inhibitor, \\
Angiotensin-converting enzyme inhibitor; ARB, angiotensin receptor blocker; \\
CABG, coronary artery bypass graft; $A V R$, aortic valve replacement; $C P B$, cardiopul- \\
monary bypass; $C P$, cardioplegia. & \\
&
\end{tabular}

TABLE E2. Select 14 autophagy genes upregulated or downregulated as determined by real-time polymerase chain reaction after cardiopulmonary bypass/cardioplegia (CPB/CP)

\begin{tabular}{|c|c|c|}
\hline Gene & Fold change & $P$ value (before vs after $\mathrm{CPB} / \mathrm{CP}$ ) \\
\hline Caspase-3 & 1.3 & .21 \\
\hline EIF2AK3 & 1.4 & .11 \\
\hline SNCA & 1.7 & .01 \\
\hline GABARAPL2 & 2.9 & .01 \\
\hline ATG4D & 1.4 & .92 \\
\hline BCL2L1 & 1.6 & .05 \\
\hline TNFSF10 & 1.4 & .01 \\
\hline$G A A$ & 1.3 & .21 \\
\hline mTOR & -1.6 & .01 \\
\hline$A T G 4 B$ & 1.8 & .34 \\
\hline ATG4A & 1.9 & .04 \\
\hline ATG4C & 1.5 & .03 \\
\hline BAK1 & 1.2 & .61 \\
\hline HSPA8 & 1.7 & .06 \\
\hline \multicolumn{3}{|c|}{$\begin{array}{l}C P B \text {, Cardiopulmonary bypass; } C P \text {, cardioplegia; } E I F 2 A K 3 \text {, eukaryotic initiation } \\
\text { factor } 2 \text { A kinase; SNCA, a-synuclein; BCL2L1, B-cell lymphocyte 2-like } \\
\text { protein-1; TNFSF10, tumor necrosis factor; GAA, acid-alpha glucosidase; } \\
m T O R \text {, mammalian target of rapamycin; } A T G 4 B \text {, autophagy-related 4B, cysteine pep- } \\
\text { tidase; ATG4A, autophagy-related 4A, cysteine peptidase; } A T G 4 C \text {, autophagy-related } \\
\text { 4C, cysteine peptidase; BAK1, B-cell lymphocyte homologous antagonist/killer 1; } \\
\text { GABARAPL2, GABA(A) receptor-associated protein-like 2; HSPA8, heat shock } 70 \\
\text { kDa protein 8. }\end{array}$} \\
\hline
\end{tabular}

